\title{
Polymorphism of the porcine $C G A$ gene and its association with growth and carcass traits
}

\author{
Xiaoling Jiang, Lifan Zhang, Ningying Xu\#, Jipeng Zhai \& Zunzhou Lv
}

College of Animal Science, Zhejiang University, Hangzhou, Zhejiang 310029, P.R. China

\author{
Copyright resides with the authors in terms of the Creative Commons Attribution 2.5 South African Licence. \\ See: http://creativecommons.org/licenses/by/2.5/za \\ Condition of use: The user may copy, distribute, transmit and adapt the work, but must recognise the authors and the South African \\ Journal of Animal Science
}

\begin{abstract}
Glycoprotein hormones in the pituitary gland affect a myriad of biological processes such as development, growth, metabolic control and gametogenesis. The quantitative trait loci (QTL) near their common glycoprotein $\alpha$ subunit gene $(C G A)$ have been reported inconsistently. The aim of this study was to dissect potential genetic factors for these unstable results and validate the association or linkage relationship of $C G A$ gene with growth and carcass traits. By resequencing all the exons and part of the introns of the porcine $C G A$ gene, 22 polymorphisms in total were identified in this study. Five single nucleotide polymorphism (SNP) markers were chosen and evaluated in six pure-bred pig breeds $(\mathrm{n}=228)$. Breedspecific haplotypes were found and a map of the porcine CGA polymorphisms' evolution history was inferred. A resource family $(n=365)$ with different genetic backgrounds from those used in other papers was used to perform an association study. The resource family was created based on crosses of Pietrain and Jinhua pigs (Central China type pigs). Results indicated that a low correlation between haplotype blocks may abolish each other's effects. Moreover, a significant association of SNP C-925T with growth rate and backfat thickness in this study confirmed the existence of previously reported QTL. SNP C-925T and SNP $\mathrm{A}+15599 \mathrm{G}$ could be useful linkage markers and SNP C-925T may also be a candidate causative SNP for the corresponding traits. Further investigation for variants within of the $C G A$ promoter region and their association with growth rate and back-fat traits is suggested.
\end{abstract}

Keywords: Common glycoprotein $\alpha$ subunit gene, haplotype, SNP, tetra-primer ARMS, swine

${ }^{\#}$ Corresponding author: nyxu@zju.edu.cn

\section{Introduction}

The glycoprotein hormones form a family consisting of the luteinizing hormone (LH), folliclestimulating hormone (FSH) and thyrotrophin (TSH) in the anterior pituitary. The general biological roles of LH and FSH are the stimulation of testicular and ovarian functions via the regulation of gametogenesis and steroid hormone synthesis in the gonads, whereas TSH stimulates the thyroid gland to produce and release the thyroid hormones, 3,3',5,5'-tetraiodothyronine (T4) and 3,3',5-triiodothyronine (T3), which affect a myriad of biological processes such as skeletal maturation, linear growth, lipid synthesis and lipolysis, and carbohydrate metabolism (Yen, 2001). The thyroid hormones also potentiate the effects of many other hormones such as insulin, the growth hormone $(\mathrm{GH})$, glucocorticoids and glucagon, and has been frequently called a permissive hormone (Bolander, 2004).

Each of the glycoprotein hormones is a heterodimer, formed by the non-covalent association of an $\alpha$ subunit that is common in all the members of the family with distinct $\beta$ subunits that confer hormone specificity (Bolander, 2004). The common $\alpha$ subunit of these hormones, encoded by the unique, single-copy gene, $C G A$ (also named as GSU $\alpha$ ), is important to receptor binding and signal transduction (Szkudlinski et al., 1996). No inactivating mutations of the CGA gene have been detected in humans and mice yet (Kendall et al., 1995; Huhtaniemi \& Alevizaki, 2007), for its widespread consequences in the form of 
hypogonadism, hypothyroidism and so on. Mice with the $C G A$ gene knockout were viable, but exhibited severe growth insufficiency and infertility (Kendall et al., 1995).

The porcine CGA gene is located on the p arm of Sus scrofa chromosome 1 (SSC 1) and consists of four exons and three introns (Kato et al., 1991). A microsatellite marker in the intron 1 (named as PGHAS or ALPHA) has been identified (Moran, 1993) and used in genetic studies. Considering the extensive effects of the glycoprotein hormones, especially TSH, their common CGA gene shows to be a promising candidate gene for economic important traits. However, comparing with the large number of Quantitative trait loci (QTL) that have been mapped on SSC 1, there are only a limited number of QTL adjacent to the CGA gene, and they have only been reported in some studies (Malek et al., 2001; Beeckmann et al., 2003; Evans et al., 2003; Liu et al., 2007) and were undetectable in others (Rohrer \& Keele, 1998; Bidanel et al., 2001; De Koning et al., 2001; Beeckmann et al., 2003; Rohrer et al., 2006; Liu et al., 2007; Edwards et al., 2008).

To dissect potential genetic factors for these inconsistent results and validate the association or linkage relationship of the CGA gene with the growth and carcass traits, a resource family with different genetic backgrounds from those used in other studies was utilized. The resource family was created based on crosses of Pietrain and Jinhua pig (Central China type pigs). First, DNA variations of the sequence of the CGA gene were identified by resequencing all exons and part of the introns. Single nucleotide polymorphisms (SNP) were chosen to develop new SNP markers for association analyses. Prior to the association analyses, the SNP markers were evaluated in six pure-bred pigs including pure-bred Pietrain and Jinhua pig breeds to construct breed-specific haplotypes and investigate their evolution history. Both porcine $C G A$ haplotypes and single SNP were analyzed in the association study to examine the association of variants with growth and carcass traits.

\section{Materials and Methods}

Genomic DNA samples were obtained from 622 pigs: 228 belonged to six pure-bred breeds (57 Yorkshire, 30 Duroc, 27 Landrace, 24 Pietrain, 49 Jinhua pigs, 41 Jiaxing Black pigs) and the others to a three-generation resource family from crosses of Pietrain and Jinhua pigs. The resource population was created by first mating three Pietrain boars and three sows to two Jinhua pig sows and three boars, respectively. Seven litters of $F_{1}$ individuals were produced. From six of the seven $F_{1}$ litters, six boars and 23 sows were chosen to produce 39 litters of $F_{2}$ animals. Besides, two of the $F_{1}$ boars were also mated back to the two founder Jinhua sows, and three of the $F_{1}$ sows were mated back to the Pietrain boars. DNA samples were extracted from whole blood or ear samples using the traditional phenol and chloroform method (Sambrook et al., 2001). The concentrations of DNA samples were measured by spectrophotometer and each was diluted to $10 \mathrm{ng} / \mu \mathrm{L}$, exactly.

Growth and carcass traits of $34 \mathrm{~F}_{1}, 36$ backcross and $295 \mathrm{~F}_{2}$ individuals were used in the association study. Growth traits analyzed included birth weight and average daily gain (ADG) from birth to weaning, from weaning to 180 days of age and from birth to 180 days of age. The carcass traits analyzed were head weight, carcass weight, ham weight, ham-muscle weight, ham external fat weight, carcass length, leaf-fat weight, back-fat thickness (BFT) at shoulder, between the $6^{\text {th }}$ and $7^{\text {th }}$ ribs, at last rib and last lumbar, and average BFT of these four positions; colour parameters (CIE L ${ }^{*}, \mathrm{a}^{*}, \mathrm{~b}^{*}, \mathrm{c}^{*}, \mathrm{~h}^{\circ}$ ) of longissimus dorsi muscle (LM), $\mathrm{pH}$ and conductivity of ham muscle and LM at $45 \mathrm{~min}$ post mortem, LM area, water-holding capacity and intramuscular protein, fat and water content.

To scan the porcine $C G A$ gene for DNA sequence variations, the direct sequencing method was employed using DNA from $4 \mathrm{~F}_{1}$ boars, 1 Pietrain and 1 Jinhua pig. The porcine $C G A$ sequence was obtained from the Ensembl database (http://www.ensembl.org/Sus_scrofa/Info/Index) using the Sscrofa9 assembly. Upstream sequence of the gene was also obtained and aligned to the sequence published by Kato et al. (1991) to target the 5'-untranslated exon 1. Figure 1 describes the gene structure and the polymorphisms identified by alignment (shown as solid lines). Five sets of primers were designed to amplify all exons and part of the introns. The amplicons were sequenced in both directions. Sequence traces were assembled with the Seqman program (DNAStar, USA) and analyzed to search for SNP.

The tetra-primer amplification refractory mutation system (ARMS) PCR procedure (Ye et al., 2001) was utilized here for SNP genotyping. This method employs four primers to amplify fragments representing each of the two allelic forms and a larger amplicon containing the SNP as control. Primers were designed by using the online computer program made accessible by $\mathrm{Ye}$ et al. (2001) (http://cedar.genetics.soton.ac.uk/public_html/primer1.html) for five SNP loci: C-925T, C+14547T, 
$\mathrm{C}+15065 \mathrm{~T}, \mathrm{~A}+15599 \mathrm{G}$ and $\mathrm{T}+15944 \mathrm{~A}$. Genotyping PCR was performed in a total volume of $10 \mu \mathrm{L}$ containing $20 \mathrm{ng}$ of template DNA, appropriate concentration of each primer (see Table 1), $200 \mu \mathrm{M}$ dNTPs, $1 \mu \mathrm{L} 10 \mathrm{x}$ buffer and $0.4 \mathrm{U}$ of Taq polymerase (TaKaRa, Dalian, China). The PCR profile was the following: an initial step of denaturation of 3 min step at $94{ }^{\circ} \mathrm{C}$; then 35 cycles of 30 seconds at $94{ }^{\circ} \mathrm{C}, 1 \mathrm{~min}$ at respective annealing temperature and $1 \mathrm{~min}$ at $72{ }^{\circ} \mathrm{C}$; and the final extension step was for 10 min at $72{ }^{\circ} \mathrm{C}$. The PCR products were separated by standard electrophoresis on $2 \%$ agarose gels.

Genotype and allele frequencies of the five SNPs in six pig pure-breds were calculated using PopGen32 software (Yeh et al., 1999). Then, haplotypes were constructed by program PHASE (Stephens \& Donnelly, 2003) and visualized in Haploview software (Barrett et al., 2005). Linkage disequilibrium between SNPs was estimated with D' and $\mathrm{r}^{2}$, and the linkage blocks were defined using the four gamete rule (Wang et al., 2002).

Haplotypes of the resource family were inferred by program, PedPhase 3.0 ( $\mathrm{Li} \& \mathrm{Li}, 2009$ ). Polymorphism $\mathrm{C}+14547 \mathrm{~T}$ was omitted from further analyses because of its serious amplification failure. Afterwards, associations between the haplotypes or genotypes of the $C G A$ gene and the investigated traits were assessed using the SAS MIXED procedure (SAS Institute Inc.). The model used was:

$$
Y_{i j k l}=\mu+H_{i}+S_{j}+L_{k}+\beta * X_{i j k l}+e_{i j k l}
$$

Where $Y_{\mathrm{ijkl}}=$ phenotypic value of traits; $\mu$ = population mean; $\mathrm{H}_{\mathrm{i}}=$ fixed effect of haplotype or genotype; $S_{j}=$ fixed effect of sex; $L_{k}=$ random effect of litter; $\beta=$ regression coefficient; $X_{i j k l}=$ live weight at slaughter as a covariate for carcass traits; and $\mathrm{e}_{\mathrm{ijk}}=$ random residual error. Multiple comparisons of least square means were adjusted with Bonferroni correction.

\section{Results}

The complete $C G A$ gene was located on SSC 1 from position 58,190,063 to 58,206,411. A schematic representation of the porcine $C G A$ gene and the identified SNPs are shown in Figure 1. Eleven potential polymorphisms were identified by comparison of the sequence obtained from the Ensembl database with that published by Kato et al. (1991). Fourteen polymorphic loci were detected by direct sequencing in this study, three of which were identical to the ones identified by sequence comparison.

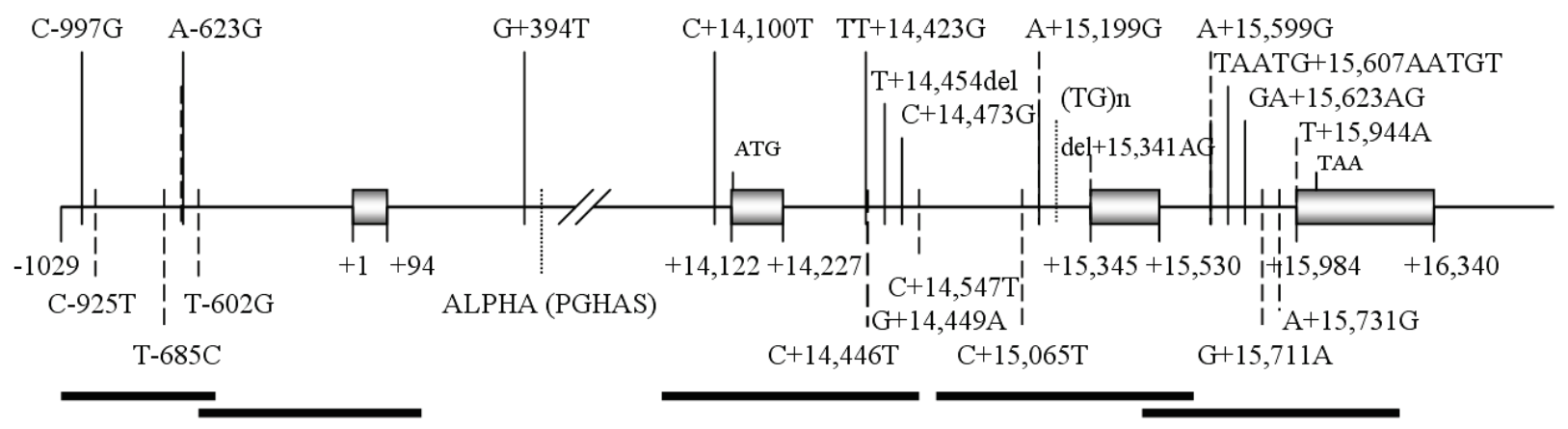

Figure 1 Schematic illustration of the porcine $C G A$ gene and its sequence polymorphisms. Exons are presented by boxes and the transcription starting site is denoted as +1 . Sequence variations identified by comparing the publicly available sequences are marked with solid lines, while the 14 polymorphisms detected by resequencing in this study are marked with dashed lines. Dotted lines represent the two microsatellites of $C G A$ gene, i.e. ALPHA and (TG) $)_{n}$. The positions of the polymorphisms are assigned according to the DNA sequence of Sscorfa 9 assembly. Resequenced regions are shown with bold horizontal lines in the lower panel.

Five SNPs: C-925T, C+14547T, C+15065T, A+15599G and T+15944A were selected to be genotyped by the tetra-primer ARMS PCR procedure (representative genotyping results are shown in Figure 2). Genotypic and allelic frequencies in six pure-bred pig breeds at these five loci are presented in Table 2. SNP $\mathrm{C}+14547 \mathrm{~T}$ segregated in Chinese breeds, while SNP loci $\mathrm{C}+15065 \mathrm{~T}$ and A+15599G were the only polymorphic in Western breeds. 
Haplotypes were constructed by the program, PHASE, and the haplotype frequencies of each breed were calculated and presented in Table 3. Haplotype CCCGT existed nearly in all breeds, whereas haplotype CTCGT and TTCGT are only shared in Chinese breeds. Haplotype CCCAT, CCTGT and CCTAT are only shared in Western breeds. CCCGA and TCCGA are common in Jinhua pig, but are also found in Yorkshire and Pietrain breeds. Haplotype CCTGA was detected only in the Pietrain breed.

Table 1 Tetra-primers ARMS-PCR genotyping

\begin{tabular}{|c|c|c|c|c|}
\hline Primer Name & Primer Sequence (5'-3') & Conc* & $\mathrm{T}_{\mathrm{A}}$ & Products (bp) \\
\hline C-925T-inF & GGAACGGAAAGAAATCAACTTATAAC & 0.4 & \multirow{4}{*}{57} & C: 122 \\
\hline C-925T-inR & AATCAGAGTTGTTCTGTGATTTATTATATA & 0.4 & & $\mathrm{~T}: 95$ \\
\hline C-925T-ouF & AAACTATGGAAGAAGATAATGGAAAT & 0.08 & & \multirow{2}{*}{ Control: 161} \\
\hline C-925T-ouR & GAGAGTTTACAACAACTCTGTAATACAAA & 0.08 & & \\
\hline $\mathrm{C}+14547 \mathrm{~T}-\mathrm{inF}$ & TATTCAGTTTAGCTCATTTTGTTTGGTGTT & 0.4 & \multirow{4}{*}{58} & C: 221 \\
\hline $\mathrm{C}+14547 \mathrm{~T}-\mathrm{inR}$ & ATGTAAAAAAAAAGCAAACAAAAGACCG & 0.4 & & T: 165 \\
\hline $\mathrm{C}+14547 \mathrm{~T}-\mathrm{ouF}$ & CATCTAGGCACTTTCAGATTGTGAACAT & 0.04 & & \multirow{2}{*}{ Control: 328} \\
\hline $\mathrm{C}+14547 \mathrm{~T}-\mathrm{ouR}$ & CAAAACAAATTTACTGCATGAAATGGTT & 0.04 & & \\
\hline $\mathrm{C}+15065 \mathrm{~T}-\mathrm{inF}$ & AGTCATGCTTGAAGAAAGAGAAACGAT & 0.8 & \multirow{4}{*}{59} & C: 151 \\
\hline $\mathrm{C}+15065 \mathrm{~T}-\mathrm{inR}$ & AGATATGCATAGGATGTCTCAACAGAAG & 0.8 & & T: 209 \\
\hline $\mathrm{C}+15065 \mathrm{~T}-\mathrm{ouF}$ & GAGAATATTTTTGCCTCTGGGTAAAATT & 0.08 & & \multirow{2}{*}{ Control: 305} \\
\hline $\mathrm{C}+15065 \mathrm{~T}-\mathrm{ouR}$ & ATGGATTTTTCCTTATTATGAGATGGTAAA & 0.08 & & \\
\hline $\mathrm{A}+15599 \mathrm{G}-\mathrm{inF}$ & AAAGAAATGTCCCCAGAGCACATACG & 0.4 & \multirow{4}{*}{63} & A: 162 \\
\hline$A+15599 G-i n R$ & AGTCGACACCTCTGGCATTAACCCTTAT & 0.4 & & G: 205 \\
\hline $\mathrm{A}+15599 \mathrm{G}-\mathrm{ouF}$ & ACAATGTTGGTTCCAAAGAACATCACCT & 0.06 & & \multirow{2}{*}{ Control: 313} \\
\hline A+15599G-ouR & СССССТСАТСАССТССАТТСТАААТААА & 0.06 & & \\
\hline $\mathrm{T}+15944 \mathrm{~A}-\mathrm{inF}$ & TCAATTTTGTCTGCCTATCTATCCGT & 0.4 & \multirow[t]{4}{*}{58} & T: 199 \\
\hline $\mathrm{T}+15944 \mathrm{~A}-\mathrm{inR}$ & AGGAAAACAAAGATAGACGATAGATAGGTT & 0.4 & & A: 134 \\
\hline $\mathrm{T}+15944 \mathrm{~A}-\mathrm{ouF}$ & ATCAGCTGAAAAGAAGAATGTGTGAATA & 0.1 & & \multirow{2}{*}{ Control: 227} \\
\hline $\mathrm{T}+15944 \mathrm{~A}-\mathrm{ouR}$ & TTAATTTTTCATTCTGAGAAATCAGCAG & 0.1 & & \\
\hline
\end{tabular}

Linkage disequilibrium between SNPs (D' and $\mathrm{r}^{2}$ ) was estimated by Haploview software. The linkage blocks defined using the four gamete rule are shown in Figure 3. SNP A+15599G and T+15944A appeared to be in complete linkage disequilibrium $\left(D^{\prime}=1\right)$, but their correlation coefficient is quite low $\left(r^{2}=0.043\right)$, indicating that one could not substitute the other one and both of them were required for providing the haplotype information. A similar relationship existed between SNP C+14547T and C+15065T. Though values of D' and $\mathrm{r}^{2}$ between SNP C-925T and others are low, lack of recombinant gamete types caused them to be correlated into one block. A recombination hot spot appears to exist between SNP C $+15065 \mathrm{~T}$ and SNP A $+15599 \mathrm{G}$.

Because of the serious amplification failure of SNP C $+14547 \mathrm{~T}$ in the resource family, this variant was omitted from further analyses. Haplotypes of the resource family were inferred by program PedPhase 3.0, and the results indicated that the founder Jinhua pigs possessed haplotypes C-CGT (i.e. $\underline{\mathrm{C}} \underline{\mathrm{CGT}} \underline{\mathrm{C} T} \underline{\mathrm{CGT}}$ )

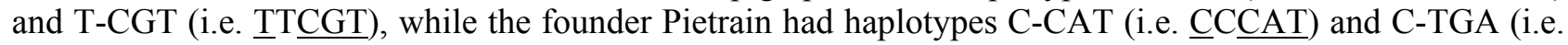


CCTGA). Recombination between the two blocks was observed in the pedigree at a rate of approximately 0.06 , and resulted in the emergence of another three haplotypes: C-CGA, C-TGT and T-CAT.

a)

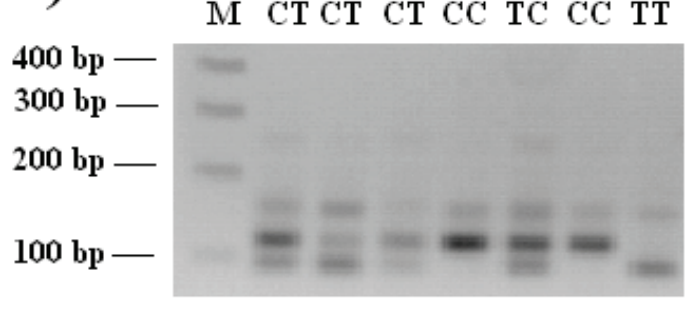

c)

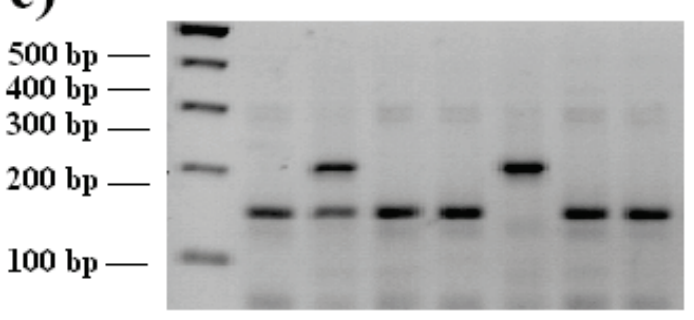

e) $\quad$ M TT TA TT TT AA TT TT

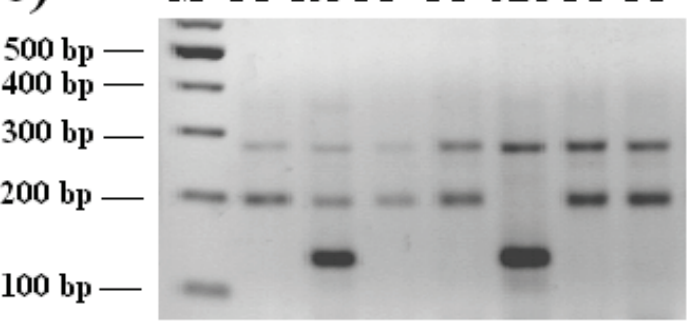

b)

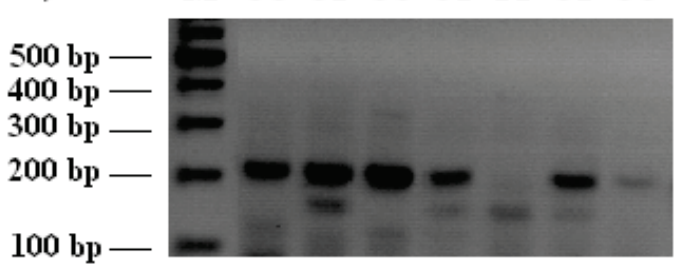

d) $M$ GA GA GA AA GA GG AA

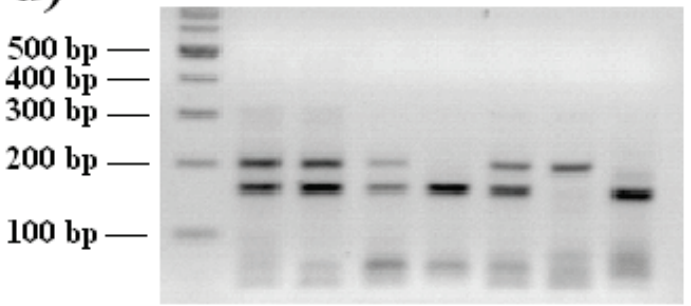

Figure 2 Genotyping results of the five SNPs by the tetra-primer ARMS-PCR procedure. Representative genotyping results for loci a) C-925T, b) C+14547T, c) C+15065T, d) A+15599G and e) T+15944A.

Association analysis showed that no traits were associated $(P<0.05)$ with the $C G A$ haplotypes. However, significant association of SNP C-925T with carcass weight, BFT at last rib and ADG, and association of SNP C+15065T with intramuscular water content were observed ( $P$ values of genetic effects are presented in Table 4). The haplotype block 1, containing these two SNPs, is significantly associated with ham external fat weight and LEA, besides BFT and ADG. But no significant differences between haplotype block 1 groups were observed in average BFT and BFT at shoulder traits using multiple comparisons adjusted by Bonferroni correction.

SNP A $+15599 \mathrm{G}$ is significantly associated with ham external fat weight, while SNP $\mathrm{T}+15944 \mathrm{~A}$ is significantly associated with intramuscular water content. Significant association of haplotype block 2 with the LM area in addition to the ham external fat weight and intramuscular water content were observed.

\section{Discussion}

The porcine $C G A$ gene is composed of four exons and three introns spanning $16,349 \mathrm{bp}$ of DNA sequence. The ATG translation starting site of this gene is in exon 2. Except for the two well-reported microsatellites, a total of 22 potential sequence variations were identified. Twelve of them were transition mutations, five were transversion mutations, and two were indel mutations. The remaining three sequence variations $(\mathrm{TT}+14423 \mathrm{G}$, TAATG+15607AATGT, GA+15723AG) cannot be put under any of the three 
classes, and that might have been caused by a sequencing error from the Kato's $C G A$ DNA sequence. No coding mutation was detected in this study.

Table 2 Genotypic and allelic frequencies at the five SNP loci in six pig pure-breds

\begin{tabular}{|c|c|c|c|c|c|c|c|}
\hline \multirow{2}{*}{ SNP } & \multirow{2}{*}{ Breed } & & \multicolumn{3}{|c|}{ Genotypic Frequency } & \multicolumn{2}{|c|}{ Allelic Frequency } \\
\hline & & & AA & $\mathrm{AB}$ & $\mathrm{BB}$ & A & $\mathrm{B}$ \\
\hline \multirow{6}{*}{ C-925T } & Yorkshire & 57 & 0.983 & 0.018 & 0.000 & 0.991 & 0.009 \\
\hline & Duroc & 30 & 1.000 & 0.000 & 0.000 & 1.000 & 0.000 \\
\hline & Landrace & 27 & 1.000 & 0.000 & 0.000 & 1.000 & 0.000 \\
\hline & Pietrain & 24 & 1.000 & 0.000 & 0.000 & 1.000 & 0.000 \\
\hline & Jinhua & 49 & 0.816 & 0.184 & 0.000 & 0.908 & 0.092 \\
\hline & Jiaxing Black & 41 & 1.000 & 0.000 & 0.000 & 1.000 & 0.000 \\
\hline \multirow[t]{6}{*}{$\mathrm{C}+14547 \mathrm{~T}$} & Yorkshire & 44 & 1.000 & 0.000 & 0.000 & 0.000 & 0.000 \\
\hline & Duroc & 19 & 1.000 & 0.000 & 0.000 & 0.000 & 0.000 \\
\hline & Landrace & 20 & 1.000 & 0.000 & 0.000 & 0.000 & 0.000 \\
\hline & Pietrain & 21 & 1.000 & 0.000 & 0.000 & 0.000 & 0.000 \\
\hline & Jinhua & 42 & 0.691 & 0.262 & 0.048 & 0.821 & 0.179 \\
\hline & Jiaxing Black & 33 & 0.091 & 0.879 & 0.030 & 0.530 & 0.470 \\
\hline \multirow[t]{6}{*}{$\mathrm{C}+15065 \mathrm{~T}$} & Yorkshire & 55 & 0.727 & 0.218 & 0.055 & 0.836 & 0.164 \\
\hline & Duroc & 24 & 0.792 & 0.125 & 0.083 & 0.854 & 0.146 \\
\hline & Landrace & 25 & 0.920 & 0.080 & 0.000 & 0.960 & 0.040 \\
\hline & Pietrain & 22 & 0.044 & 0.609 & 0.304 & 0.364 & 0.636 \\
\hline & Jinhua & 47 & 1.000 & 0.000 & 0.000 & 1.000 & 0.000 \\
\hline & Jiaxing Black & 39 & 1.000 & 0.000 & 0.000 & 1.000 & 0.000 \\
\hline \multirow[t]{6}{*}{$A+15599 G$} & Yorkshire & 56 & 0.054 & 0.269 & 0.679 & 0.188 & 0.929 \\
\hline & Duroc & 30 & 0.200 & 0.633 & 0.167 & 0.517 & 0.483 \\
\hline & Landrace & 27 & 0.000 & 0.222 & 0.778 & 0.111 & 0.889 \\
\hline & Pietrain & 24 & 0.208 & 0.667 & 0.125 & 0.542 & 0.458 \\
\hline & Jinhua & 49 & 0.000 & 0.000 & 1.000 & 0.000 & 1.000 \\
\hline & Jiaxing Black & 41 & 0.000 & 0.000 & 1.000 & 0.000 & 1.000 \\
\hline \multirow[t]{6}{*}{$\mathrm{T}+15944 \mathrm{~A}$} & Yorkshire & 56 & 0.857 & 0.143 & 0.000 & 0.929 & 0.071 \\
\hline & Duroc & 27 & 1.000 & 0.000 & 0.000 & 1.000 & 0.000 \\
\hline & Landrace & 26 & 1.000 & 0.000 & 0.000 & 1.000 & 0.000 \\
\hline & Pietrain & 23 & 0.217 & 0.783 & 0.000 & 0.609 & 0.391 \\
\hline & Jinhua & 49 & 0.265 & 0.551 & 0.184 & 0.541 & 0.459 \\
\hline & Jiaxing Black & 41 & 1.000 & 0.000 & 0.000 & 1.000 & 0.000 \\
\hline
\end{tabular}

Based on the haplotype frequencies among six pig breeds, haplotype CCCGT appeared to be the ancestral type. Then, a mutation of $\mathrm{C}$ to $\mathrm{T}$ at locus $\mathrm{C}+14547 \mathrm{~T}$ occurred and segregated in Chinese pigs, while a mutation of $\mathrm{G}$ to $\mathrm{A}$ at locus $\mathrm{A}+15599 \mathrm{G}$ and a mutation of $\mathrm{C}$ to $\mathrm{T}$ at locus $\mathrm{C}+15065 \mathrm{~T}$ occurred in Western breeds (Figure 4). The recombination existing between SNP C+15065T and A+15599G generated the new haplotype, CCTAT in Western breeds.

Segregation of SNP T+15944A and SNP C-925T occurred in Jinhua pig. Recombination between SNP $\mathrm{C}-925 \mathrm{~T}$ and $\mathrm{C}+14547 \mathrm{~T}$ generated the haplotype, TTCGT. The two microsatellites in CGA gene may act as 
Table 3 Haplotype frequencies of $C G A$ gene in six pure-bred pig breeds

\begin{tabular}{lcccccc}
\hline Haplotypes $^{1}$ & Jiaxing Black & Jinhua & Pietrain & Duroc & Landrace & Yorkshire \\
\hline CCCGT & 0.622 & 0.365 & & 0.389 & 0.846 & 0.579 \\
CTCGT & 0.378 & 0.135 & & & & \\
TTCGT & & 0.042 & & & & 0.070 \\
CCCGA & & 0.406 & 0.083 & & & 0.009 \\
TCCGA & & 0.052 & & & & 0.184 \\
CCCAT & & & 0.333 & 0.482 & 0.115 & 0.158 \\
CCTGT & & & 0.063 & 0.074 & 0.039 & \\
CCTAT & & 0.208 & 0.056 & & \\
CCTGA & & 0.313 & & & \\
\end{tabular}

${ }^{1}$ Named after the alleles of the five SNPs in order.

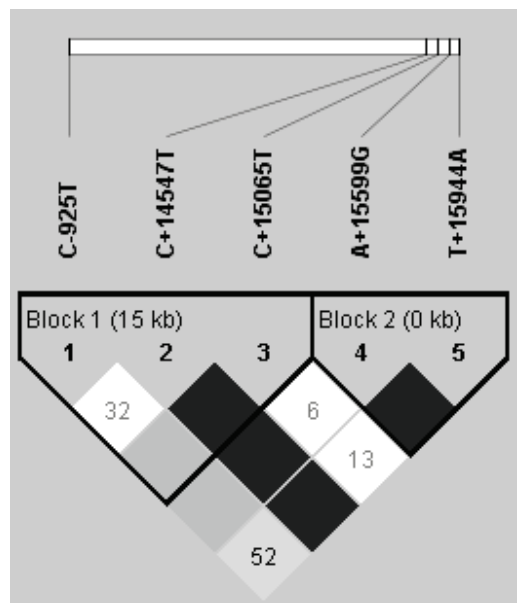

Figure 3 Linkage disequilibrium (LD) matrix plot of the five porcine $C G A$ SNP markers. The plots were produced using pair-wise D'/LOD estimates of LD with the computer program, Haploview (Barrett et al., 2005).

Table 4 Association of $C G A$ gene with carcass and growth traits in the Jinhua and Pietrain resource families (only traits significantly $(P<0.05)$ associated with SNPs of $C G A$ gene are presented)

\begin{tabular}{lcccccc}
\hline \multirow{2}{*}{ Trait } & $\mathrm{C}-925 \mathrm{~T}$ & $\mathrm{C}+15065 \mathrm{~T}$ & Block 1 & $\mathrm{A}+15599 \mathrm{G}$ & $\mathrm{T}+15944 \mathrm{~A}$ & Block 2 \\
\cline { 2 - 6 } & \multicolumn{7}{c}{$P$ values } \\
Carcass weight & $\underline{0.0261}$ & 0.776 & 0.054 & 0.752 & 0.767 & 0.948 \\
Ham fat weight & 0.162 & 0.772 & $\underline{0.021}$ & $\underline{0.024}$ & 0.771 & $\underline{0.038}$ \\
Average BFT & 0.238 & 0.664 & $\underline{0.044}$ & 0.204 & 0.685 & 0.533 \\
BFT at shoulder & 0.456 & 0.203 & $\underline{\underline{0.032}}$ & 0.272 & 0.214 & 0.303 \\
BFT at last rib & $\underline{0.013}$ & 0.955 & $\underline{0.06}$ & 0.228 & 0.991 & 0.704 \\
LM area & 0.203 & 0.927 & $\underline{\underline{0.015}}$ & 0.064 & 0.941 & $\underline{0.025}$ \\
Intramuscular water & 0.811 & $\underline{0.023}$ & 0.140 & 0.404 & $\underline{0.034}$ & $\underline{0.011}$ \\
ADG $^{1}$ & $\underline{0.015}$ & 0.319 & $\underline{0.038}$ & 0.556 & 0.396 & 0.767 \\
ADG $^{2}$ & $\underline{0.021}$ & 0.921 & 0.069 & 0.183 & 0.963 & 0.630 \\
\hline
\end{tabular}

$P$ value of genetic effects $<0.05$ underlined; BFT - Back-fat thickness; LM - Longissimus dorsi muscle; $\mathrm{ADG}^{1}$ Average daily gain from birth to weaning; $\mathrm{ADG}^{2}$ - from birth to 180 days. 
Table 5 Least square means of significantly associated traits of SNP C-925T and A+15599G

\begin{tabular}{|c|c|c|c|}
\hline \multirow{2}{*}{ Traits } & \multicolumn{3}{|c|}{ Genotype of C-925T } \\
\hline & $\mathrm{CC}$ & $\mathrm{CT}$ & TT \\
\hline Carcass weight (kg) & $55.5 \pm 0.28^{1}$ & $53.8 \pm 0.71$ & $51.8 \pm 1.48$ \\
\hline BFT at last rib (cm) & $2.30^{\mathrm{b}} \pm 0.038$ & $2.38^{\mathrm{ab}} \pm 0.098$ & $2.97^{\mathrm{a}} \pm 0.216$ \\
\hline ADG - birth to weaning $(\mathrm{g} / \mathrm{d})$ & $175.5^{\mathrm{b}} \pm 3.18$ & $201.6^{\mathrm{a}} \pm 8.37$ & $181.1^{\mathrm{ab}} \pm 15.69$ \\
\hline \multirow[t]{3}{*}{ ADG - birth to $180 \mathrm{~d}(\mathrm{~g} / \mathrm{d})$} & $345.4^{\mathrm{b}} \pm 5.41$ & $392.6^{\mathrm{a}} \pm 14.36$ & $331.4^{\mathrm{ab}} \pm 29.97$ \\
\hline & \multicolumn{3}{|c|}{ Genotype of $A+15599 G$} \\
\hline & AA & $\mathrm{AG}$ & GG \\
\hline Ham external fat weight $(\mathrm{kg})$ & $1.86^{\mathrm{b}} \pm 0.044$ & $1.96^{\mathrm{ab}} \pm 0.026$ & $2.02^{\mathrm{a}} \pm 0.039$ \\
\hline
\end{tabular}

${ }^{1}$ Least square means \pm standard errors; ${ }^{\text {a, b }}$ Row means with different superscripts differ significantly at $P<0.05$. BFT - Back-fat thickness; ADG - Average daily gain.

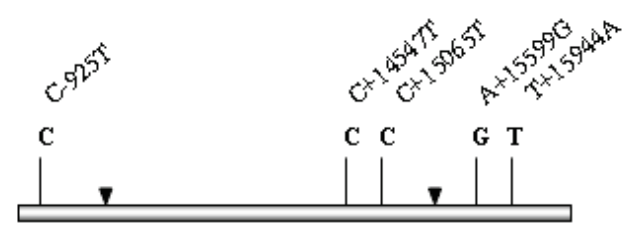

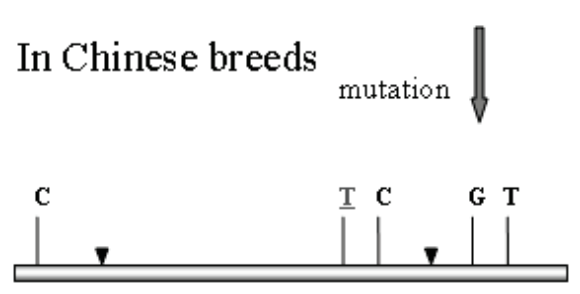

In some Chinese breeds
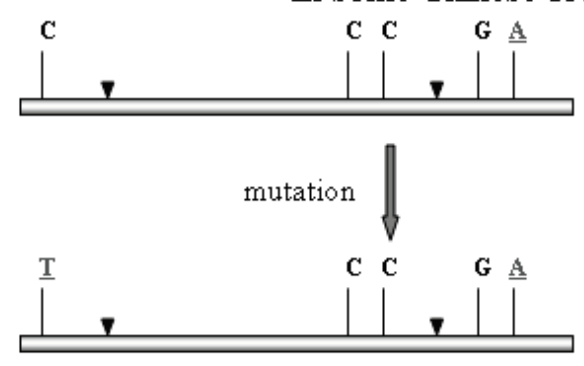

Recombine with haplotype CTCGT

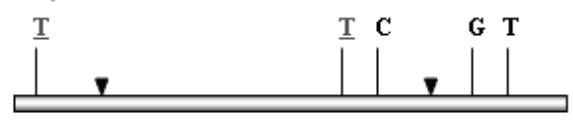

In Western breeds

mutation
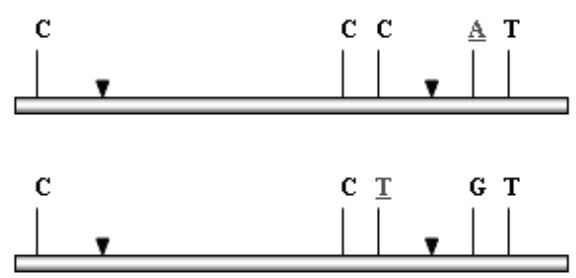

recombination

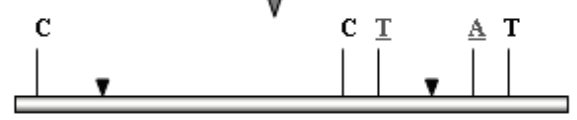

In Pietrain

Recombination between

Haplotype CCTGT and CCCGA

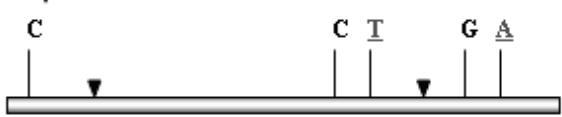

Figure 4 Deduced evolution history of the porcine $C G A$ haplotypes. The triangles represent the two microsatellites which may act as recombination hot spots in the $C G A$ gene. 
recombination hot spots. The Jinhua pig is classified as a Central China pig breed type (Li et al., 2004), while the Jiaxing Black pig, a subpopulation of Taihu pigs which include the well-known Meishan pig, belongs to the lower Changjiang Basin type. Whether these two polymorphisms exist only in some Chinese breed types but not in the others, remains to be investigated. Haplotypes CCCGA and TCCGA in Yorkshire and Pietrain pigs are likely to have originated from Chinese pig breeds, as the use of Chinese breeds with typical European breeds was popular in the $18^{\text {th }}$ century (Cesar et al., 2010). Particularly in Pietrain, recombination between the Chinese pig-originated haplotype CCCGA and the Western pig-originated haplotype CCTGT generated a new haplotype CCTGA, which is common in this breed. Absence of the ancestral haplotype in Pietrain may be due to its low frequency in the population and the small sample size used in this study.

Association analysis in the resource family showed that allele $\mathrm{T}$ from the Jinhua pig at locus C-925T was associated with lower carcass weight and higher back-fat thickness at the last rib, and the heterozygotes showed significantly faster growth rates than the homozygotes (Table 5). However, when incorporating the SNP C $+15065 \mathrm{~T}$, i.e. using block 1 as genetic factor, the association possibility decreased. This suggested that only SNP C-925T, which locates in the promoter region, may be the candidate causative SNP or in linkage at a high $\mathrm{r}^{2}$ with the causative SNP which is responsible for these traits' variations. Our results confirmed the existence of QTLs adjacent to the CGA region for carcass composition, growth rate and backfat thickness which have been reported previously (Malek et al., 2001; Beeckmann et al., 2003; Liu et al., 2007). Variations in the promoter region of CGA gene, but not the other gene components might be the candidates for these QTLs and further investigation is worthwhile.

Allele A at locus $\mathrm{A}+15599 \mathrm{G}$, which is present in Western breeds, was significantly associated with lower ham external fat weight. A QTL for ham external fat weight on SSC1 in the European wild boar and Pietrain resource family has been reported by Beeckmann et al. (2003), and the CGA SNP A+15599G could be in linkage with the causative SNP for this QTL. Interestingly, haplotype block 1 also showed significant association with ham external fat weight, but combining the haplotype block 1 and SNP A+15599G decreased the association possibility. This result may be due to the low correlation between these markers.

The A allele of $\mathrm{T}+15944 \mathrm{~A}$ and the $\mathrm{T}$ allele of SNP C+15065T originated from the same haplotype C-TGA. Thus, it was not surprising that they had similar results in the association analysis. However, after being adjusted with the Bonferroni correction, no significant differences in intramuscular water content existed following comparisons of their least square means. Animals with block 2 diplotype, --GA/--AT, had a lower intramuscular water content. To date, no QTL for intramuscular water content adjacent to the $C G A$ region has been reported.

Thyrotropin (TSH), one of the CGA gene composing hormones, regulates the synthesis and release of thyroid hormones. The thyroid hormone could stimulate lipolysis directly and indirectly as a result of the potentiation of the effects of GH, glucocorticoid and glucagon. Many of the effects of GH are mediated by a group of hormones called insulin-like growth factors (IGF's). $G H$ and $I G F$ 's secretion will decline when thyroid hormone levels are low (Porterfield \& White, 2007). It's known that $I G F$ 's and their binding proteins are also associated with growth and fatness traits (Makgahlela et al., 2009; Switonski et al., 2010). Effects of the CGA gene on the same characters might be mediated partly by IGFs pathways. Interactions between variations of $C G A$ and $I G F$ 's were strongly suggested to exist.

\section{Conclusion}

Several novel, non-coding polymorphisms were found in the porcine $C G A$ gene in this study. Different single nucleotide polymorphisms emerged in specific pig breed populations. At least two linkage disequilibrium blocks were detected in the $C G A$ gene. It is suggested that the two microsatellites in this area may act as the recombination hot spots. Association of SNP C-925T with growth rate and back-fat thickness in this study confirmed the existence of previously reported QTL and provides evidence for the roles of SNP C-925T and SNP A+15599G in affecting specific quantitative traits. Further investigation on the CGA promoter region with the growth rate and back-fat traits is recommended.

\section{Acknowledgement}

This work has been supported by the National Natural Science Foundation of China (No: 30972078) and National S \& T Major Project (No: 2008ZX08006-003). 


\section{Reference}

Barrett, J.C., Fry, B., Maller, J. \& Daly, M.J., 2005. Haploview: analysis and visualization of LD and haplotype maps. Bioinformatics 21, 263-265.

Beeckmann, P., Schroffel, J., Moser, G., Bartenschlager, H., Reiner, G. \& Geldermann, H., 2003. Linkage and QTL mapping for Sus scrofa chromosome 1. J. Anim. Breed. Genet. 120, 1-10.

Bidanel, J.P., Milan, D., Iannuccelli, N., Amigues, Y., Boscher, M.Y., Bourgeois, F., Caritez, J.C., Gruand, J., Le Roy, P., Lagant, H., Quintanilla, R., Renard, C., Gellin, J., Ollivier, L. \& Chevalet, C., 2001. Detection of quantitative trait loci for growth and fatness in pigs. Genet. Sel. Evol. 33, 289-309.

Bolander, F.F., 2004. Molecular Endocrinology. $3^{\text {rd }}$ ed. Elsevier Ltd. Oxford, UK. pp. 31.

Cesar, A.S.M., Silveira, A.C.P., Freitas, P.F.A., Guimaraes, E.C., Batista, D.F.A., Torido, L.C., Meirelles, F.V. \& Antunes, R.C., 2010. Influence of Chinese breeds on pork quality of commercial pig lines. Genet. Mol. Res. 9, 727-733.

De Koning, D.J., Rattink, A.P., Harlizius, B., Groenen, M.A.M., Brascamp, E.W. \& Van Arendonk, J.A.M., 2001. Detection and characterization of quantitative trait loci for growth and reproduction traits in pigs. Livest. Prod. Sci. 72, 185-198.

Edwards, D.B., Ernst, C.W., Raney, N.E., Doumit, M.E., Hoge, M.D. \& Bates, R.O., 2008. Quantitative trait locus mapping in an F-2 Duroc x Pietrain resource population: II. Carcass and meat quality traits. J. Anim. Sci. 86, 254-266.

Evans, G.J., Giuffra, E., Sanchez, A., Kerje, S., Davalos, G., Vidal, O., Illan, S., Noguera, J.L., Varona, L., Velander, I., Southwood, O.I., de Koning, D.J., Haley, C.S., Plastow, G.S. \& Andersson, L., 2003. Identification of quantitative trait loci for production traits in commercial pig populations. Genetics $164,621-627$.

Huhtaniemi, L. \& Alevizaki, M., 2007. Mutations along the hypothalamic-pituitary-gonadal axis affecting male reproduction. Reprod. Biomed. Online 15, 622-632.

Kato, Y., Ezashi, T., Hirai, T. \& Kato, T., 1991. The gene for the common alpha-subunit of porcine pituitary glycoprotein hormone. J. Mol. Endocrinol. 7, 27-34.

Kendall, S.K., Samuelson, L.C., Saunders, T.L., Wood, R.I. \& Camper, S.A., 1995. Targeted disruption of the pituitary glycoprotein hormone alpha-subunit produces hypogonadal and hypothyroid mice. Gene. Dev. 9, 2007-2019.

Li, S.J., Yang, S.H., Zhao, S.H., Fan, B., Yu, M., Wang, H.S., Li, M.H., Liu, B., Xiong, T.A. \& Li, K., 2004. Genetic diversity analyses of 10 indigenous Chinese pig populations based on 20 microsatellites. J. Anim. Sci. 82, 368-374.

Li, X. \& Li, J., 2009. An almost linear time algorithm for a general haplotype solution on tree pedigrees with no recombination and its extensions. J. Bioin. Comput. Biol. 7, 521-545.

Liu, G., Jennen, D.G.J., Tholen, E., Juengst, H., Kleinwachter, T., Holker,, M., Tesfaye D., Un, G., Schreinemachers, H.J., Murani, E., Ponsuksili, S., Kim, J.J., Schellander, K. \& Wimmers, K., 2007. A genome scan reveals QTL for growth, fatness, leanness and meat quality in a Duroc-Pietrain resource population. Anim. Genet. 38, 241-252.

Makgahlela, M.L., Fan, B., Du, Z.Q. \& Rothschild, M.F., 2009. Investigation of effects of three candidate genes on leg action and fat deposition traits in pigs. S. Afr. J. Anim. Sci. 39, 127-130.

Malek, M., Dekkers, J.C.M., Lee, H.K., Baas, T.J. \& Rothschild, M.F., 2001. A molecular genome scan analysis to identify chromosomal regions influencing economic traits in the pig. I. Growth and body composition. Mamm. Genome 12, 630-636.

Moran, C., 1993. Microsatellite repeats in pig (Sus domestica) and chicken (Gallus domesticus) genomes. J. Hered. 84, 274-280.

Pierce, J.G. \& Parsons, T.F., 1981. Glycoprotein hormones - structure and function. Annu. Rev. Biochem. 50, 465-495.

Porterfield, S.P. \& White, B.A., 2007. Endocrine Physiology. $3^{\text {rd }}$ ed. Mosby Inc, St Louis, USA. pp 124-152.

Rohrer, G.A. \& Keele, J.W., 1998. Identification of quantitative trait loci affecting carcass composition in swine: I. Fat deposition traits. J. Anim. Sci. 76, 2247-2254.

Rohrer, G.A., Thallman, R.M., Shackelford, S., Wheeler, T. \& Koohmaraie, M., 2006. A genome scan for loci affecting pork quality in a Duroc-Landrace F-2 population. Anim. Genet. 37, 17-27.

Sambrook, J, Fristsch, E.F. \& Maniatis, T., 2001. Molecular cloning: A laboratory manual. $3^{\text {rd }}$ ed. Cold Spring Harbor Laboratory, New York, USA. 
Stephens, M. \& Donnelly, P., 2003. A comparison of Bayesian methods for haplotype reconstruction from population genotype data. Am. J. Hum. Genet. 73, 1162-1169.

Switonski, M., Stachowiak, M., Cieslak, J., Bartz, M. \& Grzes, M., 2010. Genetics of fat tissue accumulation in pig: a comparative approach. J. Appl. Genet. 51, 153-168.

Szkudlinski, M.W., Grossmann, M. \& Weintraub, B.D., 1996. Structure-function studies of human TSH New advances in design of glycoprotein hormone analogs. Trends Endocrin. Met. 7, 277-286.

Wang, N., Akey, J.M., Zhang, K., Chakraborty, R. \& Jin, L., 2002. Distribution of recombination crossovers and the origin of haplotype blocks: The interplay of population history, recombination, and mutation. Am. J. Hum. Genet. 71, 1227-1234.

Ye, S., Dhillon S., Ke, X.Y., Collins, A.R. \& Day, I.N.M., 2001. An efficient procedure for genotyping single nucleotide polymorphisms. Nucleic Acids Res. 29, art. no.-e88.

Yeh, F.C., Yang, R.C. \& Boyle T., 1999. POPGENE Version 1.31, Microsoft window-based freeware for population genetic analysis. University of Alberta, Canada.

Yen, P.M., 2001. Physiological and molecular basis of thyroid hormone action. Physiol. Rev. 81, 1097-142. 